\title{
La problemática del territorio y las ciudades en El Salvador
}

La entrada en vigencia, en julio de 2012, de la esperada Ley de Ordenamiento y Desarrollo Territorial (DL644/2011), así como de la Ley de Lotificaciones (DL 993/2012) a partir de septiembre de este año y el prolongado debate sobre el anteproyecto de Ley de Vivienda de Interés Social en la misma Asamblea Legislativa son señales inequívocas del interés que existe en la estructura formal del Estado salvadoreño acerca de los temas relacionados con la organización y el uso del territorio.

Y es que el territorio es un elemento fundamental en el proceso de desarrollo de cualquier país y, por diversas razones, lo es con más apremio en El Salvador. Lo ha sido prácticamente desde los años cincuenta, cuando la agenda de modernización incorporó elementos de intervención del Estado para promover su ordenamiento y desarrollo. Al centro de la discusión de aquel entonces, aparecieron nuevas instituciones públicas, algunas de las cuales subsisten hasta nuestros días -como la Comisión Ejecutiva Portuaria Autónoma (CEPA), la Comisión Ejecutiva Hidroeléctrica del Río Lempa (CEL)-, mientras que otras perecieron en el proceso de reforma neoliberal de los noventa -como el Instituto de Vivienda Urbana (IVU) o la Dirección de Urbanismo y Arquitectura (DUA)-. En todo caso, el debate acerca del uso del territorio en El Salvador durante el siglo XX estuvo dominado por la cuestión agraria, la regulación de la propiedad rural y el aprovechamiento de los recursos naturales.

En El Salvador del siglo XXI, la discusión se mueve hacia otros temas, como lo demuestran las leyes antes mencionadas, pero sobre todo profundos procesos de transformación territorial que, a menudo, pasan desapercibidos en el análisis de la coyuntura pública. En la última década, después de los terremotos de 2001, hay más claridad sobre la existencia de una población mayoritariamente urbana; el impacto y recurrencia de grandes desastres, como sismos, inundaciones o derrumbes; el creciente protagonismo de los gobiernos locales en la vida nacional. Todo esto, entre otros factores, configura la necesidad de abordar el desarrollo territorial como una política pública clave para el desarrollo sostenible del país.

En paralelo, en el nuevo siglo se ha consolidado un pensamiento y una práctica desde el Estado y la sociedad civil alrededor de disciplinas vinculadas con el territorio, tales como el desarrollo local y el ordenamiento territorial. Además, se ha reiterado, al menos en un sentido declarativo, un propósito de descentralización y reforma del Estado. Todo ello apunta a posicionar 
al territorio como una variable clave para hacer política pública, con lo cual lo territorial se confirma como una dimensión central de la problemática del desarrollo en El Salvador.

Diversos documentos y estudios de los últimos diez años subrayan esta situación desde diferentes perspectivas, por ejemplo: al analizar los retos ambientales y de desarrollo urbano (PNUD, 2003; PNODT, 2004; FUSADES, 2008; FLACSO, 2010); al identificar apuestas de desarrollo económico (CND, 1998; ENADE, 2009; STP, 2010); cuando se analizan las problemáticas sociales, de pobreza y exclusión (PNUD, 2005; PNUD, 2010) o los desafíos de la reforma institucional (FUSADES, 2009; SISCA, 2009). De ahí se desprende que el territorio, entendido desde una perspectiva sistémica, es escenario de los grandes procesos ambientales, sociales, económicos y políticos y, por lo tanto, sufre sus impactos o evidencia sus transformaciones, pero a la vez los condiciona, enmarcando potencialidades y evidenciando debilidades, contradicciones, desigualdades y exclusión. El hecho de que la administración 2009-2014 se planteara la constitución de una Subsecretaría de Desarrollo Territorial y Descentralización evidencia el carácter estratégico de esta dimensión del desarrollo. A continuación, se plantean algunas de las problemáticas estructurales del territorio y de las ciudades en el país, las cuales deben servir de marco para el debate académico que este número de la revista pretende animar.

\section{Los procesos estructurales de cambio territorial}

Es posible hacer una lectura de los múltiples y simultáneos procesos de cambio territorial en El Salvador, los cuales evidencian de hecho algunas de las problemáticas estructurales del país y le plantean, por lo tanto, algunas de sus mayores oportunidades y de sus más críticos desafíos.

\section{El territorio y las transformaciones del modelo económico}

En El Salvador de la postguerra, se consolidó un modelo económico con profundas implicaciones territoriales. El modelo agroexportador tradicional, vigente durante la mayor parte del siglo $\mathrm{XX}$, fue desmontado y dio paso a una economía fundamentada en el sector servicios, el cual contribuye con casi dos terceras partes de la riqueza nacional y genera igual proporción del empleo. Como parte de esa misma dinámica, la agricultura perdió importancia tanto en volumen como en el valor de su producción, ya que esta apenas contribuye con poco más del $12 \%$ del PIB y emplea una quinta parte de la población activa (BCR, 2011). Quiere decir que el territorio rural salvadoreño se ha visto profundamente afectado, tanto por la pérdida de valor relativo de su producción como por su limitada capacidad de generar trabajo $y$, por ende, por su marginación dentro del sistema económico vigente. Por otra parte, actividades económicas como el turismo rural y la agroforestal siguen siendo incipientes, por lo que no se han consolidado como ejes productivos alternativos. 
El cambio de modelo también ha replanteado las maneras en las que el país se vincula a los mercados mundiales. Las exportaciones nacionales dependen ahora en un $90 \%$ de la maquila y de los productos no tradicionales, desde bienes industriales hasta nuevos productos agroindustriales, cuya producción y oferta de empleo se concentra en espacios muy específicos del área metropolitana de San Salvador (AMSS) y de los corredores de la carretera Panamericana, de la carretera a Sonsonate - Acajutla y del entorno del aeropuerto internacional. Todo esto ha estrechado la relación comercial con Estados Unidos y con América Central, y paralelamente ha contribuido a desarticular los espacios rurales respecto al aparato exportador nacional, el cual ha pasado a ser cada vez más urbano.

Lo anterior se evidencia en la concentración de más de tres cuartas partes de los ingresos fiscales del Gobierno nacional en el AMSS, particularmente en los municipios de San Salvador, Santa Tecla y Antiguo Cuscatlán (Trigueros, 2005), así como en la fragilidad de los ingresos fiscales provenientes del resto del país.

En paralelo, se ha mantenido el flujo de migrantes salvadoreños al exterior, especialmente hacia Estados Unidos, multiplicándose con ello la importancia de las remesas para la economía nacional. Estas remesas representan, aproximadamente, una quinta parte del PIB y tres cuartas partes de las exportaciones nacionales y llegan con regularidad a uno de cada cinco hogares. En el nordeste del país, se han consolidado regiones que permanentemente expulsan población y se han establecido nuevas redes transnacionales que afectan la gobernabilidad local y las dinámicas familiares. Esto concuerda con la distribución territorial de la pobreza, la cual

En el nordeste del país, se han consolidado regiones que permanentemente expulsan población y se han establecido nuevas redes transnacionales que afectan la gobernabilidad local y las dinámicas familiares adquiere mayor severidad en ese mundo rural excluido donde saltan a la vista condiciones críticas de acceso a servicios básicos, infraestructura y equipamientos sociales.

Quiere decir que una parte esencial de la economía de El Salvador y de las fuerzas productivas que estructuran su territorio se encuentra conectada a dinámicas globales más amplias, se localiza en los espacios urbanos, en detrimento de los rurales y se articula a otros procesos sociales por medio del empleo y el flujo de remesas. Esta situación ha multiplicado las desigualdades territoriales en términos del acceso a oportunidades de desarrollo.

\section{Nuevas formas de ocupar el territorio, vulnerabilidad ambiental y exclusión}

En los últimos veinte años, El Salvador claramente ha pasado a ser un país urbano, tanto por las nuevas dinámicas económicas como por la continua concentración de población en este tipo de asentamientos. Según el censo de 2007, al menos dos tercios de los salvadoreños viven en los es- 
pacios urbanos, por lo que -junto a Panamá- es el país más urbanizado de América Central.

De lejos, la mayor concentración urbana del país sigue siendo el área metropolitana de San Salvador (AMSS), con 1.6 millones de habitantes en 2007, la cual ha seguido extendiéndose linealmente a lo largo de los principales ejes viales, rebasando los límites administrativos de los catorce municipios del área metropolitana. De hecho, los municipios de esa periferia alejada -Tonacatepeque, Colón, San Juan Opico, Quezaltepeque, San José Villanueva, Zaragoza y Olocuilta- son los que, según el censo, han demostrado una mayor presión de crecimiento demográfico y físico en las décadas recientes.

Un proceso novedoso que emerge dentro de ese nuevo país urbano es el acelerado crecimiento de nuevos subsistemas urbanos intermedios fuera del AMSS. Los datos demográficos llaman la atención sobre: 1) Valle de San Andrés; 2) Santa Ana; 3) Chalchuapa - Ahuachapán; 4) Sonsonate Acajutla; 5) aeropuerto - Zacatecoluca; 6) Usulután; 7) San Miguel. Estas ciudades o conurbaciones tienen en su conjunto una población urbana similar al AMSS y, sin embargo, poseen en general menores capacidades para gestionar el nuevo crecimiento que enfrentan (FUNDE, 2004). En todo caso, es notable que en El Salvador los procesos de restructuración de la actividad productiva y la urbanización apuntan consistentemente hacia mayores niveles de concentración de población y, por lo tanto, de demanda de servicios y aprovechamiento de recursos naturales en la franja central y costera del país.

Cobra especial importancia la precariedad de las condiciones de vivienda de, al menos, una tercera parte de los hogares salvadoreños, según los datos oficiales del censo
Paralelo a ese proceso de urbanización, es notoria la degradación de zonas ambientalmente estratégicas, como las cuencas de los ríos Lempa, Acelhuate, Suquiapa, Sonsonate, Sucio, Jiboa y Grande (de San Miguel), que justamente atraviesan los principales sistemas urbanos. Este proceso incluye la contaminación por vertidos no tratados, la erosión y la ocupación de zonas de recarga. La urbanización de zonas altas del territorio conlleva un aumento de las amenazas ambientales y de los niveles de peligrosidad, lo cual se agrava en un contexto global de cambio climático, ante el cual apenas comienzan los esfuerzos más estructurales de adaptación.

De igual forma, en estos espacios urbanos en expansión se han incrementado las desigualdades sociales, la exclusión y la violencia. El "Mapa de pobreza urbana y de exclusión social" (PNUD, 2010) alertaba con claridad acerca del rostro cada vez más urbano de la pobreza y la exclusión en el país. Esta última no puede disociarse del tema de la violencia, la cual se presenta como un fenómeno territorialmente diferenciado, ya que son algunos municipios y ciertas zonas de las grandes ciudades las que concentran la mayor parte de la actividad delictiva, con las subsiguientes consecuencias en términos de inversión, paralización de la dinámica económica de los territorios y desempleo. 
Por ello, cobra especial importancia la precariedad de las condiciones de vivienda de, al menos, una tercera parte de los hogares salvadoreños, según los datos oficiales del censo: ausencia de servicios básicos (notablemente en la provisión de agua potable y disposición de aguas servidas); deficiencia de materiales constructivos; inseguridad en la tenencia de 300000 predios según la Ley de Lotificaciones; limitado acceso a equipamientos sociales; pésimo servicio de transporte público; a esto se agrega, al menos en el área metropolitana, una raquítica disponibilidad de espacios públicos abiertos: apenas $4 \mathrm{~m}^{2}$ por habitante en San Salvador. Todo ello debería alertar sobre la pobre calidad de los espacios urbanos en crecimiento y las contradicciones sociales que encuban.

En todo caso, resulta claro que en El Salvador se configuran de forma paralela dos realidades territoriales diferenciadas: por un lado, ciertas zonas del centro-occidente del país, particularmente el AMSS, concentran las actividades económicas dominantes, son generadoras de empleos y concentran cada vez más población y exclusión; y por otro, el resto del país, especialmente el nordeste enfrentando condiciones de rezago social y de falta de dinamismo económico. Todo ello en un marco de creciente vulnerabilidad social y fragilidad ante la ocurrencia de eventos naturales. Esto significa que, en El Salvador, a la consabida desigualdad social hay que agregar una creciente desigualdad territorial. Así como es posible identificar grupos sociales excluidos de las oportunidades de desarrollo, aparece también que hay territorios de exclusión. Por ello, es ineludible plantear la dimensión territorial de los procesos de desarrollo y del cambio social.

\section{Limitadas formas de gestión del territorio}

Además, de lo económico productivo, lo cultural, lo urbano o lo ambiental, el territorio está marcado por un orden institucional que cristaliza la manera en la que la sociedad lo regula, protege o aprovecha. El marco legal que viabiliza la gestión del territorio en El Salvador sigue siendo incoherente $e$ insuficiente. Persiste una legislación centralista y sectorial en temas de gran impacto territorial, vale repasar: la Ley de Urbanismo y Construcción, la de la Administración Nacional de Acueductos y Alcantarillados (ANDA), de Caminos y Carreteras, de CEL o de CEPA.

Esta legislación se contrapone a otras piezas más descentralizadoras, como el Código Municipal, la Ley de Ordenamiento y Desarrollo Territorial del AMSS, la de Medio Ambiente, la del Fondo de Desarrollo Económico y Social (FODES), a las que más recientemente se ha agregado la Ley de Ordenamiento y Desarrollo Territorial. En ese marco, persisten la falta de coordinación entre instituciones del Gobierno nacional, los vacíos de competencias entre el nivel nacional y local y sus conflictos, y la muy lenta institucionalización de modalidades más participativas de gestión. También es notoria la falta de una institucionalidad capaz de articular en el territorio la intervención de instituciones como Obras Públicas, Transporte, Economía, Gobernaciones e instancias de Desarrollo Local y Municipal. El lanzamiento y aparente éxito de programas sociales territorialmente focalizados, como "Comunidades So- 
lidarias" o territorialmente articulados como "Territorios de Progreso" ponen en evidencia las limitaciones del quehacer estatal tradicional.

Por otra parte, la escasez de recursos y débil recaudación local resulta dramática. Las transferencias del Gobierno nacional a los gobiernos locales (FODES) representan la mitad de los ingresos locales, situación que se agrava entre los municipios más pequeños. Muchos de los impuestos de vocación municipal a nivel mundial están en manos del Gobierno central y, en el peor de los casos, no existen, como el impuesto predial. En El Salvador del siglo XXI, aún falta explorar formas más potentes de recaudación en el nivel local por medio de tasas y contribuciones especiales que graven las plusvalías y aumenten la capacidad y calidad de la prestación de servicios por parte de los municipios. Todo esto contribuye a limitar aún más las po-

En síntesis, el desarrollo territorial y de las ciudades en

El Salvador depende de una cada vez más urgente reforma del Estado que potencie las capacidades locales, incluyendo la de los actores de la sociedad civil, y estructure la forma en que las diversas instituciones se articulan entre sí sibilidades institucionales para contrarrestar los desequilibrios territoriales antes anotados y para que el Estado pueda desarrollar una política territorial activa en clave de desarrollo.

Aunque ha habido avances importantes en las ultimas dos décadas, subsisten numerosas tareas pendientes en términos de un auténtico fortalecimiento de la capacidad de gestión del nivel municipal. Aquí se incluyen las reales capacidades administrativas, regulatorias, de planificación e inversión, así como la institucionalización de prácticas más democráticas en términos políticos y de participación ciudadana. En síntesis, el desarrollo territorial y de las ciudades en El Salvador depende de una cada vez más urgente reforma del Estado que potencie las capacidades locales, incluyendo la de los actores de la sociedad civil, y estructure la forma en que las diversas instituciones se articulan entre sí. De lo contrario, las leyes recientemente aprobadas corren riesgo de tener un carácter esencialmente declaratorio y contribuir a la dispersión e ineficacia de los esfuerzos.

\section{Nuevas perspectivas para orientar el desarrollo del territorio}

Este breve resumen de las problemáticas territoriales y urbanas de $\mathrm{El}$ Salvador evidencia una nueva aproximación, todavía en elaboración en el mundo académico, acerca del concepto de territorio como construcción social e histórica, configurada por las grandes variables ambientales, pero transformada de forma conflictiva por la actividad social del ser humano. Se trata de una perspectiva sistémica en la que se entiende que el territorio está conformado por una compleja red de elementos naturales y culturales interactuando entre sí y que, tal como lo anotaba Restrepo (2001), constituyen "un campo multivariado y complejo de interacciones" que se transforma en el tiempo. De ahí que el territorio se entienda además como un espacio de poder, en el que los actores públicos y privados gestionan, producen, negocian y distribuyen riqueza y oportunidades. Quiere decir que la sociedad da sentido y transforma al territorio, pero al mismo tiempo el territorio da forma 
y condiciona a la sociedad, lo cual además admite la posibilidad de conflictos, incoherencias e intereses divergentes, que en el caso salvadoreño se palpan en las problemáticas antes explicadas.

Este número monográfico de la revista ECA intenta levantar de forma inicial el debate sobre algunos de los puntos antes anunciados. Siete artículos elaborados a partir del trabajo de investigación de diversos docentes de la universidad recorren cinco elementos fundamentales de la problemática territorial del país: el impacto territorial del turismo, las ciudades intermedias y tres temas críticos urbanos: la vivienda, el espacio público y la movilidad.

Así, en la escala más amplia, se analiza el vínculo entre turismo y desarrollo territorial, y las nuevas condiciones de habitabilidad e informalidad que caracterizan algunas ciudades intermedias de El Salvador. A nivel metropolitano, se explora la relación entre desarrollo urbano y violencia, haciendo una reflexión sobre la geografía de la violencia en el país en general y en el AMSS en particular, para finalmente vincular el tema a las oportunidades de generación de nuevos espacios públicos en la ciudad. En esa misma línea, en otro trabajo, se introduce la necesidad de los procesos de animación sociocultural de cara a la construcción de espacios públicos más potentes e integradores. De igual forma, se discuten, desde una visión más sistémica, las potencialidades de un nuevo sistema de transporte público en el AMSS. Finalmente, dos trabajos se concentran en el tema de la vivienda, uno desde el ámbito de las políticas públicas en la escala municipal y el otro por medio del estudio de caso del proyecto residencial más grande del país: Altavista.

Con ello se espera insistir en dos aspectos clave acerca del estudio y las políticas públicas relativas al territorio. Primero, se trata de reconocer la dimensión sistémica, y no sectorial, de los temas territoriales, lo que plantea nuevas exigencias teórico-conceptuales y de política pública. Segundo, se quiere insistir en la oportunidad de un cambio de la realidad territorial, en sus múltiples dimensiones, a través de una serie de intervenciones e instrumentos que, en definitiva, abonen al cambio estructural que el país todavía demanda. 